\title{
Single umblical artery in a neonate: Does it matter?
}

\section{Ganavi Ramagopal*, Ganesh Narayana, Geethanjali Arivudaiselvan, Prabhu Elango, Rajendran Ramayi}

Department of Pediatrics, Dhanalakshmi Srinivasan Medical College and Hospital, Perambalur, Tamil Nadu, India

\begin{abstract}
Single umbilical artery (SUA) is one of the most frequent umbilical malformation. As an Isolated finding SUA does not markedly increase perinatal morbidity and mortality, but when it is associated with other pathologies, leads to higher perinatal loses.
\end{abstract}

Keywords: Umbilical artery, Perinatal, Morbidity, Mortality.

Accepted on December 18, 2017

\section{Case Details}

We present here a term male neonate, born to a primi mother whose antenatal ultra-sonogram [USG] showed single umbilical artery (Figure 1) and bilateral gross hydroureteronephrosis. Baby was delivered by Lower segment caesarean section, indication being cephalo pelvic disproportion. Baby cried immediately after birth and birth weight was $3.4 \mathrm{~kg}$.

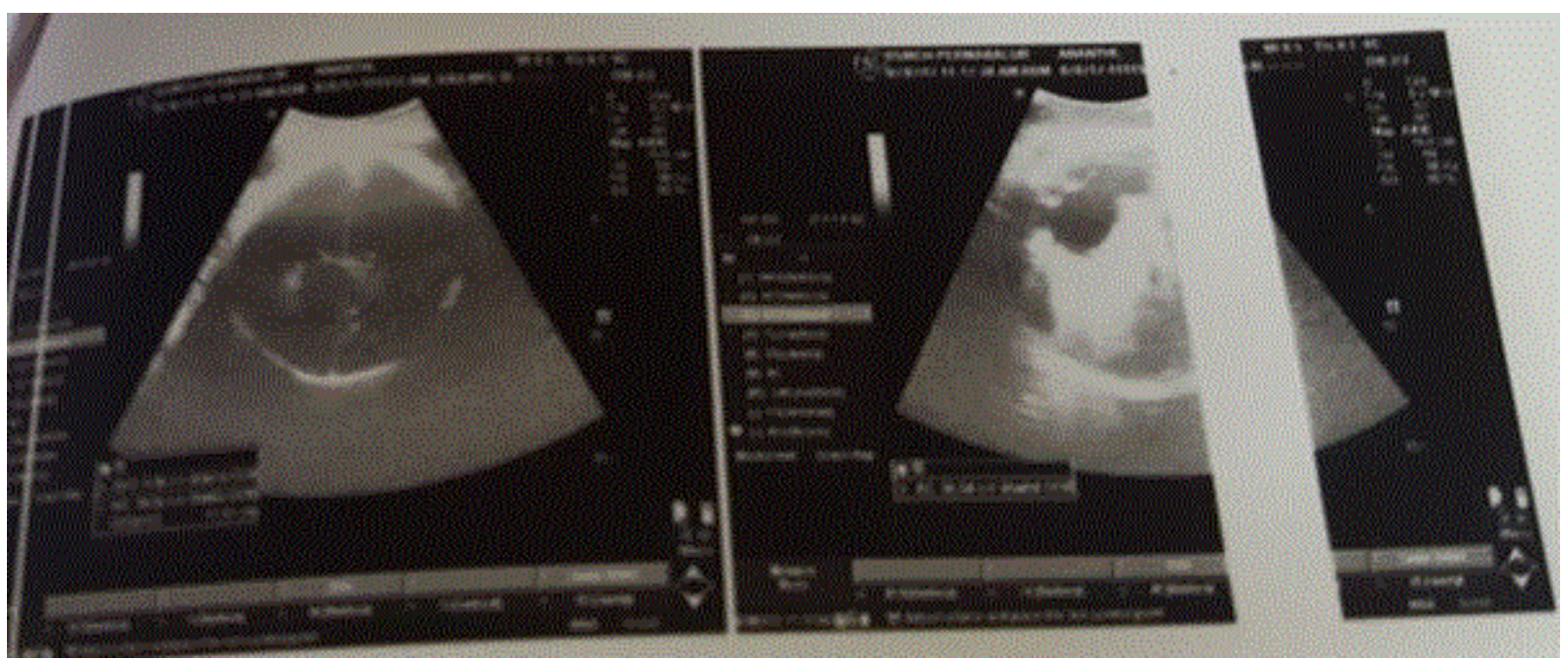

Figure 1. Antenatal USG showing Single umbilical artery.

On examination, umbilical cord showed one artery and one vein instead if two arteries and one vein and right hand showed post axial polydactyly. Baby was taking breast feeds well and postnatal period was uneventful. So as the baby had single umbilical artery and polydactyly, we evaluated and did an ultrasound Abdomen which showed bilateral hydroureteronephrosis (Figure 2) and echocardiography done revealed $5 \mathrm{~mm}$ ostium secundum ASD, 2 tiny muscular VSD, tiny PDA. Renal function test was within normal limits. Karyotyping was normal. Urologist and cardiologist opinion taken, and Baby is doing well and on regular follow up.

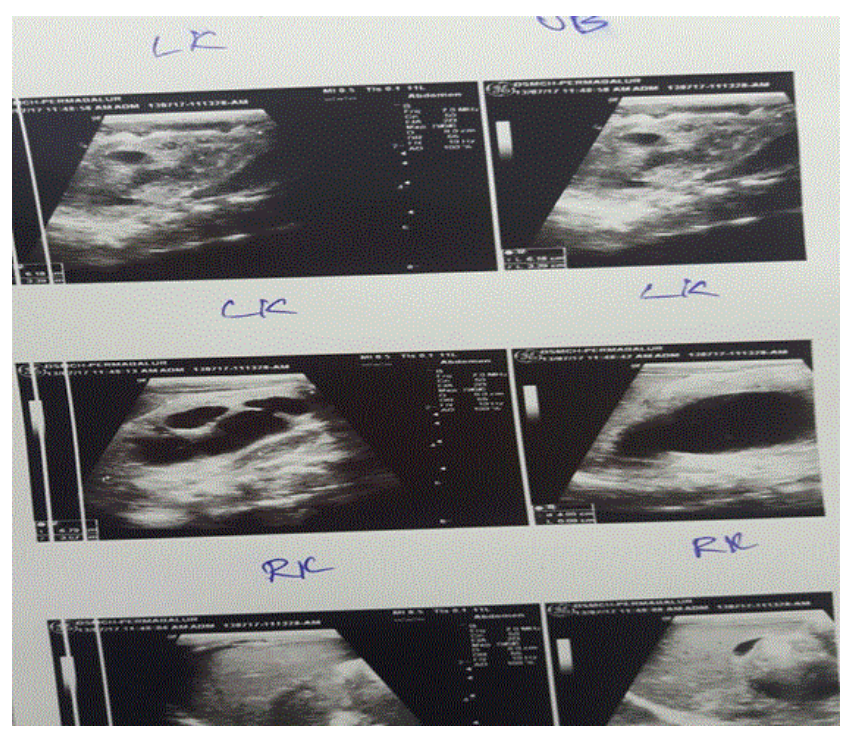

Figure 2. Usg abdomen showing bilateral hydroureteronephrosis 


\section{Discussion}

The umbilical cord usually consists two arteries and one vein. Sometimes primary agenesis or Secondary atrophy of one of the arteries occurs resulting in single umbilical artery.

SUA is the most frequent umbilical malformation the incidence varies from $0.2 \%$ to $0.87 \%$ [1]. The absence of one umbilical artery or single umbilical artery (SUA) has shown to be associated with some adverse perinatal events, that includes low birth weight, prematurity, Congenital malformations and perinatal mortality.

The most common congenital anomalies associated with SUA are renal, then followed by cardiovascular and musculoskeletal as in our case [2]. The aetiopathogenesis of SUA has not been fully explained, however, three possible mechanisms have been suggested in the embryogenesis of SUA. First, mechanism proposed is the primary agenesis of one of the umbilical arteries. Secondly, there may be secondary regression of a preexisting normally formed artery and lastly there may be persistence of the original single allantois artery of the body stalk $[3,4]$.

Regression of a pre-existing normal artery may be due to thrombotic or thrombo-embolic event leading to hemodynamic disturbances in fetal blood flow, ultimately leading to atresias and other associated anomalies [5].

SUA diagnosis should be a reason for more strict observation antenatally, appropriate timing of delivery, appropriate mode of delivery, and for more prompt intervention during delivery and postnatal period.

\section{References}

1. Vasanthalakshmi GN, Pushpalatha T, Mehta P, et al. Single umbilical artery and pregnancy outcomes: Cause for concern. J S Asian Fed Obstet Gynaecol. 2012;4:103-5.

2. Murphy-Kaulbeck L, Dodds L, Joseph KS, et al. Single umbilical artery risk factors and pregnancy outcomes. Obstet Gynecol. 2010;116:843-50.

3. Heifetz SA. Single umbilical artery: a statistical analysis of 237 autopsy cases and review of literature. Perspect Pediatr Pathol 1984;8:345-78.

4. Byrne J, Blanc WA. Malformation and chromosome anomalies in spontaneous aborted fetuses with single umbilical artery. Am J Obstet Gynecol 1985;151:340-2.

5. Monie IW. Genesis of single umbilical artery. Am J Obstet Gynecol 1970;108:400-5.

\section{*Correspondence to}

Ganavi Ramagopal

Department of Pediatrics

Dhanalakshmi Srinivasan Medical College and Hospital

Perambalur, Tamil Nadu

India

E-mail: ggganavi10@gmail.com 